\title{
Quantification of Polycyclic Aromatic Hydrocarbons in the NIST Standard Reference Material (SRM1649A) Urban Dust Using Thermal Desorption GC/MS
}

\author{
Daniel Waterman, Brian Horsfield, † Franz Leistner, ${ }^{\dagger}$ Keith Hall, ${ }^{\dagger}$ and Steve Smith* \\ Division of Life Sciences, King's College London, Franklin-Wilkins Building, 150 Stamford Street, London, SE1 8WA, U.K.
}

\begin{abstract}
A thermal desorption GC/ MS technique has been developed for the quantification of polycyclic aromatic hydrocarbons (PAHs) in airborne particulate matter using the NIST Standard Reference Material (SRM1649a) Urban Dust. The technique was developed using standard linearity tests in order to establish optimum sample weights and optimum desorption and chromatographic parameters. This direct analysis technique eliminates the use of solvents in the sample preparation (reducing volatile component losses) and also significantly reduces the sample preparation time (no extraction procedure). The technique has been shown to give linearity in terms of the overall TIC response as well as for a prominent series of n-alkanes $\left(\mathrm{C}_{20}-\mathrm{C}_{33}\right)$ and 10 NIST priority PAHs, 8 of which have been quantified. The technique is reported to be uniquely sensitive (PAH concentrations $2-6 \mathrm{mg} \mathrm{kg}^{-1}$ ) and reproducible (MW $=178-228 \mathrm{SD} \leq 0.228 \mathrm{mg} \mathrm{kg}^{-1}$, $\leq 7 \%$; $M W=252$ SD $\leq 0.922 \mathrm{mg} \mathrm{kg}^{-1}, \leq 33 \%$ ) over the range of sample weights $(1-5 \mathrm{mg})$. Such sample weights illustrate that the technique can be equally applied to the analysis of airborne particulate samples collected over short time periods ( $24-48 \mathrm{~h}$ ) using only commonly used low-volume collection devices.
\end{abstract}

The adverse health effects of airborne particulates are well recognized, and correlation between particulate concentration and incidents of respiratory problems, in particular, have been well illustrated in epidemiological studies, e.g., refs 1 and 2. Such studies have raised concerns regarding the concentration and nature of airborne particulate pollution and although inroads have been made in understanding the chemical, biological, and physical properties of airborne particulates, such work has also succeeded in defining the problem as an extremely complex one.

\footnotetext{
* To whom correspondence should be addressed: (e-mail) steve.smith@ kcl.ac.uk; (fax) 44 (0)207848 4500.

${ }^{\dagger}$ Current address: Institute of Petroleum and Organic Geochemistry, Forschungszentrum Jülich $\mathrm{GmbH}, \mathrm{D}-52425$ Jülich, Germany

‡ Current adress: Hall Analytical Laboratories Ltd., Unit A, M illbrook Business Centre, Floats Rd., M anchester M 23 9Y J, U.K.

(1) Dockery, D. W.; Pope, G. A.; Xu, X.; Spengler, J. D.; Ware, J. H.; Fay, M. E.; Ferris, B. G.; Speizer, F. E. N. Engl. J. Med. 1993, 329, 1753-1759.

(2) Pope, C. A.; Thun, M. J.; Namboodiri, M. M .; Dockery, D. W.; Evans, J. S.; Speizer, F. E.; Heath, C. W. J. Am. Respir. Crit. Care M ed. 1995, 151, 669674.
}

10.1021/ac991372x CCC: $\$ 19.00$ @ 2000 American Chemical Society Published on Web 06/29/2000
Airborne particulate matter consists of particles of variable size and composition and is often referred to as PM 10 (particles of mean aerodynamic diameter of $10 \mu \mathrm{m}$ ). A greater understanding of how particles are deposited within the respiratory system ${ }^{3}$ has meant interest, particularly in understanding the toxicity mechanism, has moved toward smaller fractions of PM 2.5, PM 1, and ultrafine fractions $(<0.1 \mu \mathrm{m})$.

Chemical characterization is important in adding to the understanding of the toxicity mechanism as well as being vital in assessing the sources of airborne particulate matter (source apportionment) and, therefore, is key to implementation of environmental policies for the reduction of major sources of particulates. As interest moves toward smaller particles, there is an increasing need for highly sensitive chemical characterization techniques that are capable of working with extremely small samples of particulate matter composed of complex mixtures of chemical species in low concentrations.

Multiple and variable source factors mean that particulate composition is extremely complex and variable. ${ }^{4} \mathrm{M}$ ethods for the analysis of the inorganic fraction of particles (elemental analysis, metals analysis, soluble ions analysis) are well established, e.g., ref 5 whereas organic analysis has relied mainly on solvent extraction techniques (Soxhlet), followed by GC/ HPLC analysis. ${ }^{6}$ When coupled to organic geochemical techniques such as biomarker analysis and source/ emission profiling, the technique has proved a useful tool for source apportionment work (for a recent review, see ref 7).

Although the Soxhlet extraction has been the primary tool of organic analysis, it can be considered to suffer from a number of limitations. The efficiency of a Soxhlet extraction depends on the solubility of the individual organic components in the selected solvent and the ability of the solvent to penetrate the matrix. Extraction is often maximized by the utilization of lengthy multiplestage extractions, multiple solvent extractions, or physical agitation such as refluxation or ultrasonication. Furthermore, the relatively

(3) Task Group of Lung Dynamics (Committee II-ICRP). Health Phys. 1996, $12,173-207$.

(4) Source Apportionment of Airborne Particulate M atter in the United Kingdom (APEG 1999). Report of the Airborne Particles Expert Group on behalf of the DETR, UK, 1999.

(5) Harrison, R. M.; Jones, M. Sci. Total Environ. 1995, 168, 195-214.

(6) Institute of Petroleum. Determination of soluble organic fraction (SOF) of diesel particulates on filters-Soxhlet extraction method. IP PM CA/ 96.

(7) Simoneit, B. R. T. Environ. Sci. Pollut. Res. 1999, 1 (3), 159-169. 
large weights of deposit required (typically $8-10 \mathrm{mg}$ ) often necessitates the bulking of samples or high-volume sampling equipment. Soxhlet extraction also suffers from being inappropriate for low molecular weight, volatile compounds, because they are either lost in the solvent reduction stage of sample preparation or are masked by the solvent itself during subsequent gas chromatographic analysis.

Improved extraction techniques have more recently been developed such as microwave digestion ${ }^{8}$ and supercritical fluid extraction ${ }^{9}$ that have been shown to provide comparable or improved extraction yields as well as being less time consuming. However, both techniques still require a separate extraction stage prior to analysis and relatively large weights of deposit.

Thermal desorption eliminates the long extraction stage, has been shown to give reproducible organic fingerprints (including more volatile compounds), and requires considerably smaller samples. It was with these factors in mind that we evaluated thermal desorption as a technique for quantifiable organic analysis of airborne particulates.

Thermal desorption has already proved to be a valuable tool in the earth science and energy sectors when coupled with online gas chromatography analysis. ${ }^{10,11}$ Environmental applications of the technique have tended to involve absorption of organics onto solid supports such as Tenax or SPME fibers prior to desorption and analysis (see ref 12 for a recent review). Typically contaminants from water ${ }^{13}$ (studies of wastewater and contaminated soils) or volatile organics in air ${ }^{14}$ have been studied by these methods.

The technique of direct thermal desorption with on-line GC is used in the oil industry for analyzing particulates collected directly from engine exhausts. The technique is not established as a quantifiable method but is used to examine the unresolved, broad fuel and lubricant peaks observed using a wide-bore GC column in order to assess the fuel mix performance. ${ }^{15}$

Pyrolysis GC/MS, a significantly more energetic technique involving considerable breakdown and fragmentation of large molecules and the solid matrix has started to be used in environmental analysis but has tended to concern studies of biomarkers in contaminated soils ${ }^{16}$ and potential applications in bioremediation work. ${ }^{17,18}$

\section{EXPERIMENTAL SECTION}

Thermal Desorption GC/MS Hardware. The thermal desorption system (illustrated in Figure 1) utilizes a Quantum MSSV-2 thermal analysis port (GC2 Chromatography and EGO

(8) Wong, M. K.; Gu, W.; Ng, T. L. Anal. Sci. 1997, 13 (55), 97-102.

(9) Oda, J. Bunseki Kagaku 1999, 48 (6), 595-607.

(10) Horsfield, B.; Disko, U.; Leistner, F. Geol. Rundsch. 1989, 78 (1), 361374.

(11) M uscio, G.; Horsfield, B.; Welte, D. H. Adv. Org. Geochem.; Øygard, K., Ed. Org. Geochem. 1994, 22 (3-5), 461-476.

(12) Fox, D. L. Anal. Chem. 1999, 71, 109R-119R.

(13) Grote, C.; Belau, E.; Levsen, K.; Wunsch, G. ACTA Hydrochim. Hydrobiol. 1999, 27 (4), 193-199.

(14) Pankow, J. F.; Luo, W.; Isabelle, L. M.; Bender, D. A.; Baker, R. J. Anal. Chem. 1998, 70, 5213-5221.

(15) Institute of Petroleum. Analysis of fuel and oil derived hydrocarbons in diesel particulates on filters-Gas Chromatography method. IP PM BZ/ 96.

(16) Medina-Vera, M. J. Anal. Appl. Pyrolysis 1996, 36, 27-35.

(17) Richnow, H. H.; Seifert, R.; Kästner, M .; M ahro, B.; Horsfield, B.; Tiedgen, U.; Böhm, S.; M ichaelis, W. Chemosphere 1995, 31 (8), 3991-3999.

(18) White, D. M.; Irvine, R. L. Environ. Monit. Assess. 1998, 50 (1), 53-65.

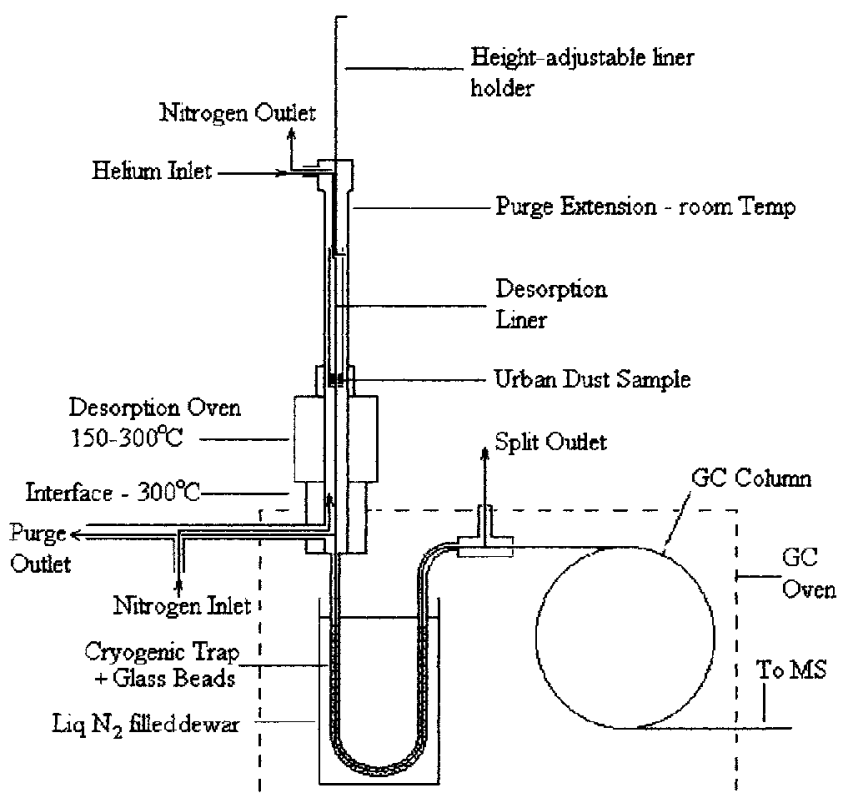

Figure 1. Thermal desorption GC/MS system.

Inc.). The unit comprises a desorption double oven mounted on the top of a Hewlett-Packard 5890 gas chromatograph, connected to a short-path interface and a direct heated cryogenic trap filled with glass beads. The interface has a purge outlet and a nitrogen back-flush facility for cleaning debris from the system. The control panel has fully programmable temperature facilities allowing separate control of the oven, the interface, and the cryogenic trap as well as programmable temperature ramping and control of the carrier gas flow rate. The cryogenic trap is cooled using a liquid nitrogen dewar internal to the GC oven that is lowered on completion of the desorption. The timing of the trap heating is integral to the GC temperature program and is monitored by the control panel.

The desorption oven has an extension to the inlet that allows ambient temperature purging of samples. The desorption liner is made of steel and is held in position by an adjustable height arm. The GC split is positioned after the cryogenic trap giving greater control of flows, resulting in better reproducibility, prior to connection to the GC capillary column (Phenomenex ZB -5, 25 m, $0.25 \mathrm{~mm}$ i.d., $0.25 \mu \mathrm{m} \mathrm{ft}$ ). The GC is interfaced to a Fisons M D 800 mass spectrometer run in $\mathrm{EI}$ mode and scanned from $\mathrm{m} / \mathrm{z} 40$ to 520.

Sample Preparation. The NIST Standard Reference M aterial SRM 1649a Urban Dust was collected using a baghouse method near to Washington, DC, and was purchased through the Laboratory of the Government Chemist (Teddington, U.K.). The material is certified for a number of polycyclic aromatic hydrocarbons $(\mathrm{mg}$ $\left.\mathrm{kg}^{-1}\right)$, for a series of PCBs $\left(\mu \mathrm{g} \mathrm{kg}^{-1}\right)$, and for total organic content and extractable (Soxhlet) organic content (note: n-alkanes are not certified).

Samples were prepared by weighing quantities of the urban dust into a glass-lined stainless steel GC liner (cleaned at $600{ }^{\circ} \mathrm{C}$ for $5 \mathrm{~min}$ ) containing a small plug ( $1 \mathrm{mg}$ ) of glass wool (cleaned at $350^{\circ} \mathrm{C}$ ). A second plug of glass wool is positioned on top of the urban dust, minimizing flow disturbances and consequent losses or displacement of material from the heated zone of the desorption oven. Internal standards could then be added as dichloromethane (DCM) solutions from a microsyringe. 


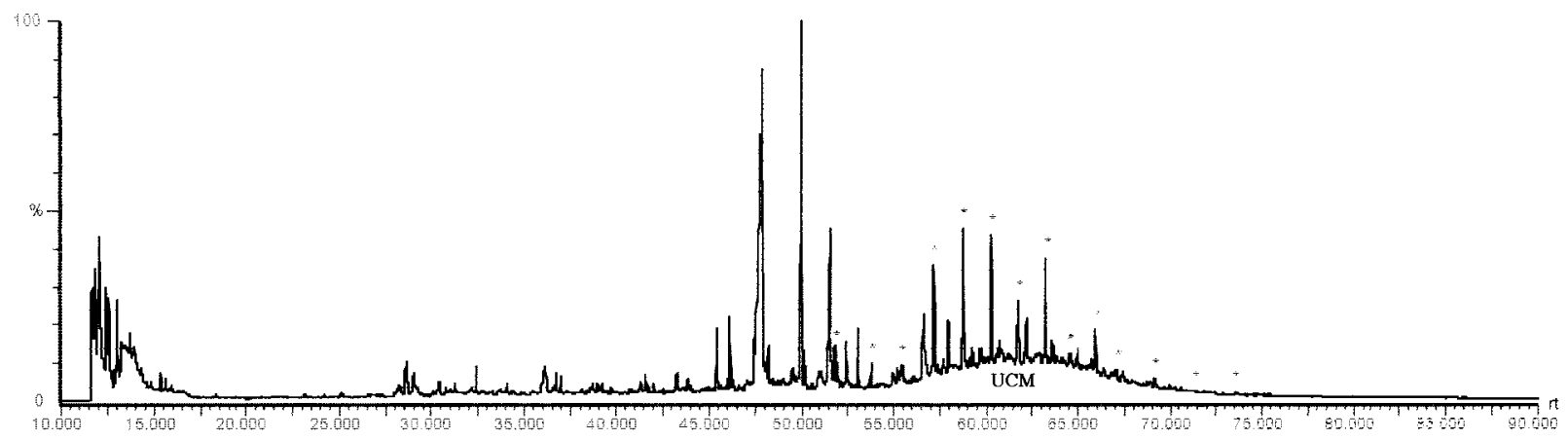

Figure 2. Chromatogram of $2.90 \mathrm{mg}$ of thermally desorbed SRM1649a Urban Dust. Asterisks indicate consecutive $n$-alkanes from $n=20$ to $n=33$.

Analytical Procedure. The GC split ratio is set (15:1) with a column flow rate of $0.8 \mathrm{~mL} \mathrm{~min}{ }^{-1}$ prior to the liner being placed in the ambient temperature purge extension of the desorption unit, and the sample is purged for $1 \mathrm{~min}$. The dewar of the cryogenic trap is then filled with liquid nitrogen and the trap submerged. The data acquisition and the GC temperature programs are started simultaneously, and the liner is lowered into the body of the desorption oven which is then ramped from 175 to $300^{\circ} \mathrm{C}$ at 50 ${ }^{\circ} \mathrm{C} \mathrm{min}^{-1}$. On vaporization, the desorbants are swept by the carrier gas from the heated zone, minimizing potential thermal decomposition, and are focused on the trap for the 10-min desorption period. The trap is then lowered and almost simultaneously flash heated from -196 to $300{ }^{\circ} \mathrm{C}$ in $20 \mathrm{~s}$, flushing the desorbants held on the trap onto the GC column for analysis. The GC oven is set at $40^{\circ} \mathrm{C}$ for $13 \mathrm{~min}$ (including desorption time) and then ramped at $5{ }^{\circ} \mathrm{C} \mathrm{min}-1$ to $300{ }^{\circ} \mathrm{C}$ and held for 25 min (total analysis time $90 \mathrm{~min})$.

Carrier gas flows are allowed to equilibrate for $\sim 5 \mathrm{~min}$ between each stage of the process and confirmed by monitoring flow rates on a Humonics Veri-Flow 500 precision low-volume flow meter. On completion of the GC program, the system is cooled, the liner is removed, and the inlet system is cleaned of fragments of glass wool and dust particles by back-flushing with a 2 bar pressure of nitrogen through the purge outlet valve. All equipment is handled using cotton gloves, and all implements used in the preparation are first cleaned with solvent and then in an oven at $350^{\circ} \mathrm{C}$.

Linearity was confirmed using different weight samples of the SRM and plotting integrated areas of the total chromatographic area (relative to blank baseline), a series of $n$-alkanes $\left(C_{20}-C_{33}\right)$ and a series of PAHs (M W 178-276), against total sample weight. Similarly linearity plots were obtained by desorbing a series of $1-\mu \mathrm{L}$ volumes of different concentrations of phenanthrene- $d_{10}$ in DCM injected onto a small quantity of glass wool in a blank liner. Suitable weights (within the linearity) of both Urban Dust and phenanthrene-d $d_{10}$ were then utilized for quantification of the PAHs.

\section{RESULTS AND DISCUSSION}

Linearity Tests. Chromatograms (example in Figure 2) were obtained from different weights of samples ( $1-5 \mathrm{mg}$ ) of SRM run under identical conditions. The chromatograms showed a general progression from high mass-high response to low mass-low response, and all peaks were present in the relative amounts in all chromatograms. Linearity was confirmed in the plot of total chromatographic area, relative to a blank run under identical

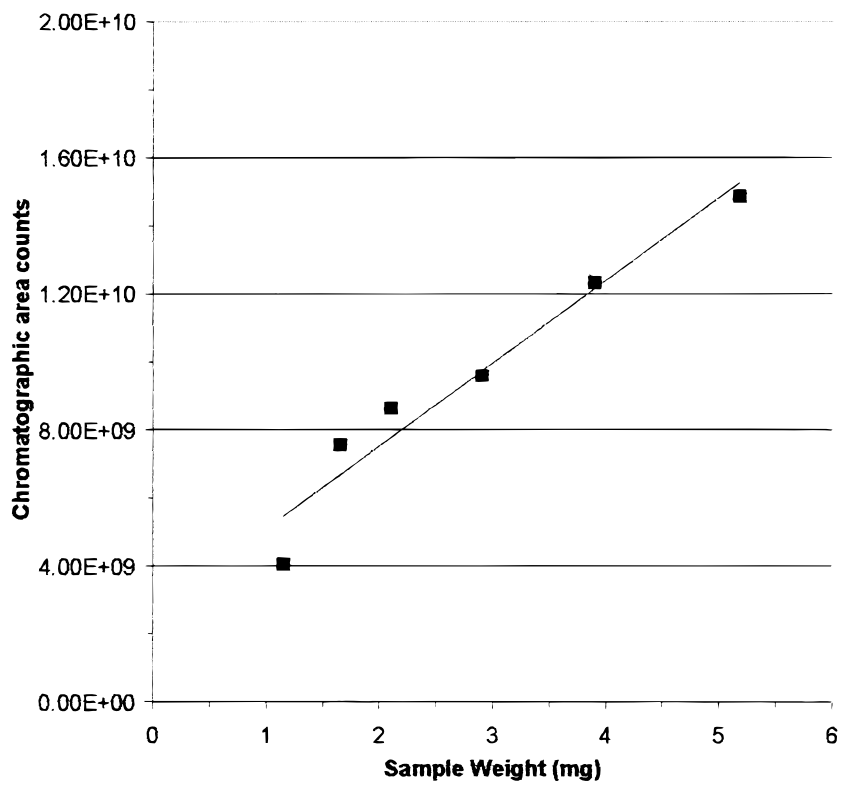

Figure 3. Chromatographic linearity $\left(R^{2}=0.948\right)$ of the Standard Reference Material SRM1649a Urban Dust.

conditions, versus total sample weight (Figure 3 ). The plot indicates good linearity $\left(R^{2}=0.948\right)$ within the range of weights used, $1-5 \mathrm{mg}$. As well as the TIC linearity, a series of $n$-alkanes $\left(\mathrm{C}_{20}-\mathrm{C}_{33}\right)$ labeled in Figure 2, were identified and the chromatographic areas plotted against sample weight illustrating good linearity in the microgram range (Figure 4).

Ten NIST priority PAHs were identified (phenanthrene, pyrene, fluoranthene, benz[a]anthracene, chrysene, benzo[b]fluoranthene, benzo[e]pyrene, benzo[a]pyrene, benzo[ghi]perylene, indeno[ 1,2,3-cd]pyrene) covering molecular weights 178276 and selected from the chromatograms and the integrated areas plotted against total sample weight (Figure 5). The plots indicate that within the range of 1-5 $\mathrm{mg}$ of urban dust a linear response for the $10 \mathrm{PAHs}$ is seen. The linearity ranges closely follow that of the total chromatographic linearity range. If then the total urban dust sample weight $(1-5 \mathrm{mg})$ is converted to PAH weight utilizing the certified values for each PAH, then the linearity range for observing PAHs is equivalent to $20-200 \mathrm{ng}$. The linearity of the PAHs is seen to have similar gradients illustrating comparable response-to-weight ratios and therefore the PAHs are directly comparable at all weights of urban dust along the linearity. The high molecular weight PAHs benzo[ ghi ] perylene and indeno[ 1,2,3- 


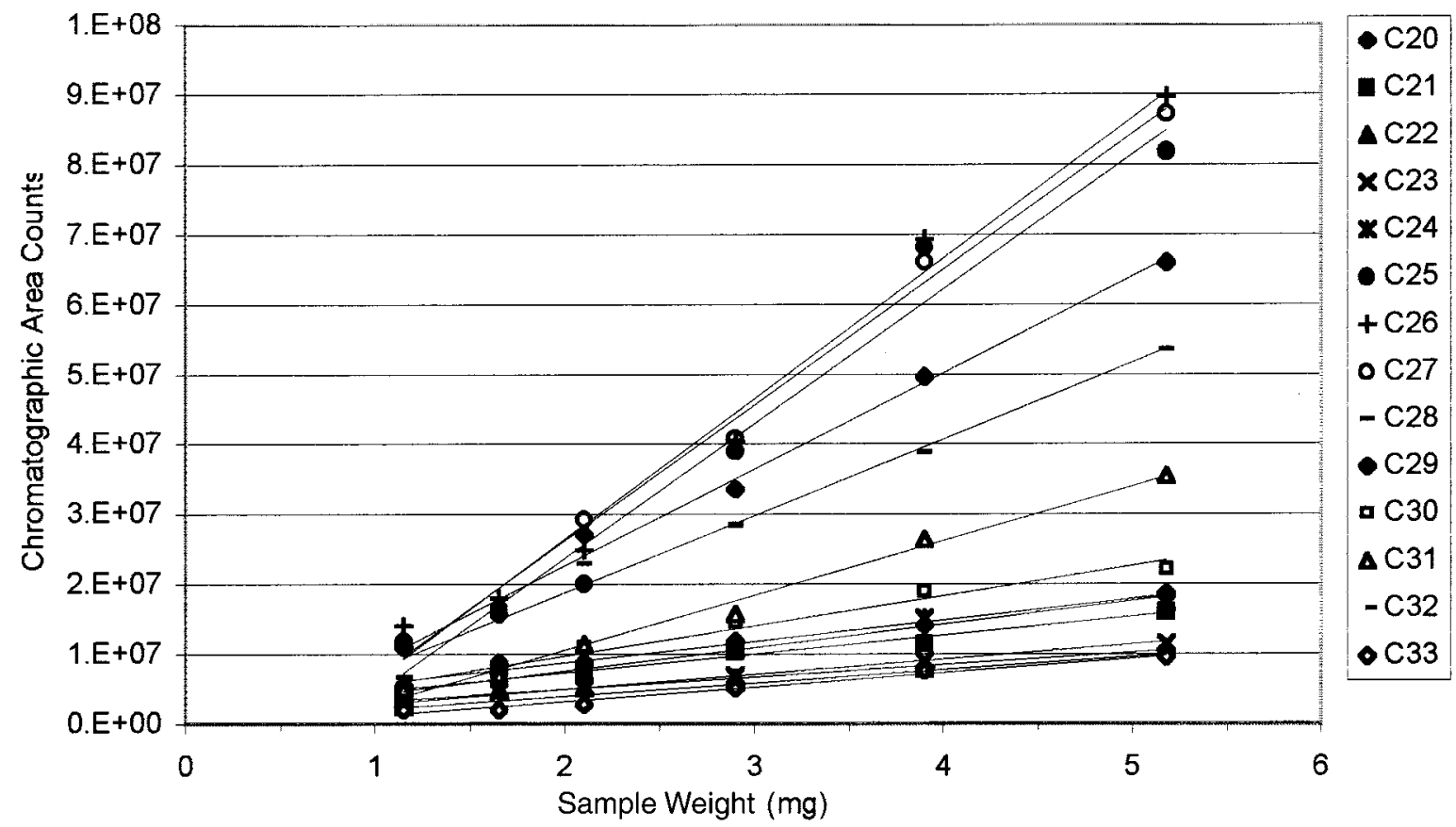

Figure 4. Chromatographic linearity of $14 n$-alkanes from $\mathrm{C}_{20}-\mathrm{C}_{33}: \mathrm{C}_{20} R^{2}=0.980, \mathrm{C}_{21} R^{2}=0.931, \mathrm{C}_{22} R^{2}=0.972, \mathrm{C}_{23} R^{2}=0.984, \mathrm{C}_{24} R^{2}$ $=0.981, \mathrm{C}_{25} R^{2}=0.972, \mathrm{C}_{26} R^{2}=0.984, \mathrm{C}_{27} R^{2}=0.993, \mathrm{C}_{28} R^{2}=0.987, \mathrm{C}_{29} R^{2}=0.992, \mathrm{C}_{30} R^{2}=0.972, \mathrm{C}_{31} R^{2}=0.991, \mathrm{C}_{32} R^{2}=0.976$, and $\mathrm{C}_{33} R^{2}=0.978$.

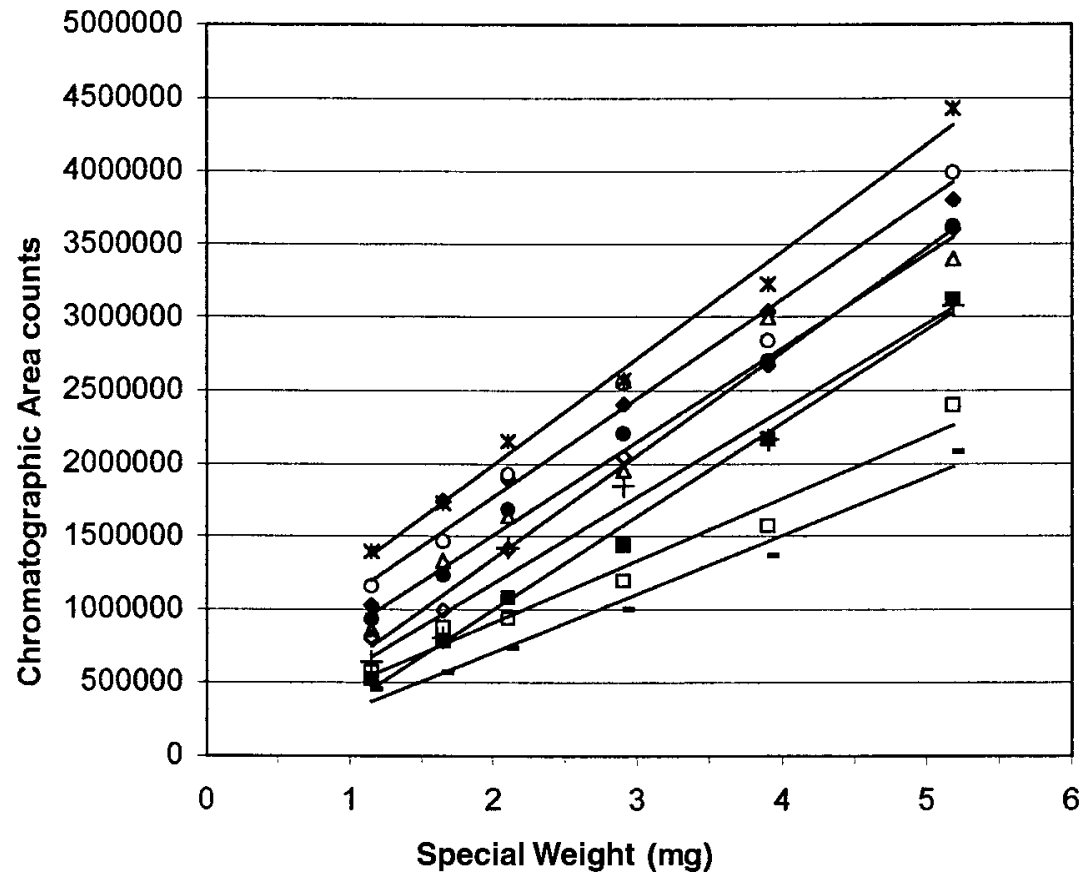

- Phenanthrene
- Pyrene
$\Delta$ Flouranthene
- benz(a)anthracene
- Chrysene
* Benzo(b)fluoranthene
- Benz(e)pyrene
+ Benz(a)pyrene
- Benzo(ghi)perylene
Indeno(1,2,3-cd)pyrene

Special Weight $(\mathrm{mg})$

Figure 5. Chromatographic linearity of $10 \mathrm{PAHs}$ (phenanthrene $R^{2}=0.983$, pyrene $R^{2}=0.982$, fluoranthene $R^{2}=0.973$, benz[a]anthracene $R^{2}=0.996$, chrysene $R^{2}=0.997$, benzo[b]fluoranthene $R^{2}=0.992$, benzo[e]pyrene $R^{2}=0.995$, benzo[a]pyrene $R^{2}=0.976$, benzo[ghi]perylene $R^{2}=0.983$, indeno[1,2,3-cd]pyrene $R^{2}=0.971$ ) in the Standard Reference Material SRM1649a Urban Dust.

cd] pyrene have the largest gradient discrepancy from the other $\mathrm{PAHs}$, indicating that comparisons of mass/response ratios between these two PAHs and the lower molecular weight PAHs will vary depending on the mass of the sample.

In order that the PAHs measured in the urban dust SRM can be quantified, an internal deuterated standard, phenanthrene- $d_{10}$ for the lower volatility certified PAHs phenanthrene, pyrene, fluoranthene, benz[a] anthracene and chrysene, was utilized. The higher molecular weight PAHs were also quantified relative to the phenanthrene- $\mathrm{d}_{10}$ standard by utilizing a NIST PAH standard in DCM run with a phenanthrene- $d_{10}$ standard, and response factors were calculated. Prior to spiking the urban dust SRM samples with phenanthrene- $d_{10}$, a series of $1-\mu \mathrm{L}$ samples of phenanthrene- $\mathrm{d}_{10}$ of differing concentrations in DCM were thermally desorbed from blank liners. A plot of chromatographic area of phenanthrene- $d_{10}$ against phenanthrene- $d_{10}$ sample weight is shown in Figure 6. Good linearity is again seen in the phenanthrene- $d_{10}$ series $\left(R^{2}=0.963\right)$ over a range of weights comparable 
Table 1. Comparison of Calculated Concentrations ( $\mathrm{mg} \mathrm{kg}^{-1}$ ) of Eight PAHs over Five Runs, Each Using Approximately $3 \mathbf{~ m g}$ of Urban Dust

\begin{tabular}{lllllllllll}
\multicolumn{1}{c}{ mg kg $^{-1}$} & run 1 & run 2 & run 3 & run 4 & run 5 & mean & SD $(\sigma)$ & $\begin{array}{c} \pm(\text { confidence } \\
95 \%)\end{array}$ & $\begin{array}{c}\text { certified } \\
\text { value }\end{array}$ & $\begin{array}{c} \pm(\text { confidence } \\
95 \%)\end{array}$ \\
phenanthrene & 4.658 & 4.502 & 4.815 & 4.657 & 4.472 & 4.621 & 0.124 & 0.109 & 4.14 & 0.37 \\
fluoranthene & 6.378 & 6.828 & 6.688 & 6.576 & 6.868 & 6.668 & 0.178 & 0.156 & 6.45 & 0.18 \\
pyrene & 5.438 & 4.898 & 5.008 & 4.938 & 4.945 & 5.055 & 0.199 & 0.175 & 5.29 & 0.25 \\
benz[a]anthracene & 2.523 & 2.238 & 2.142 & 3.478 & 2.956 & 2.859 & 0.191 & 0.167 & 2.21 & 0.073 \\
chrysene & 3.455 & 3.318 & 3.925 & 3.365 & 3.700 & 3.655 & 0.228 & 0.200 & 3.049 & 0.06 \\
benzo[b]fluoranthene & 6.030 & 5.410 & 5.656 & 7.372 & 6.536 & 6.201 & 0.780 & 0.684 & 6.450 & 0.640 \\
benzo[e]pyrene & 3.913 & 3.322 & 3.992 & 2.671 & 4.061 & 3.592 & 0.652 & 0.571 & 3.090 & 0.190 \\
benzo[a]pyrene & 2.830 & 2.103 & 2.480 & 2.392 & 4.141 & 2.789 & 0.922 & 0.809 & 2.509 & 0.087 \\
\hline
\end{tabular}

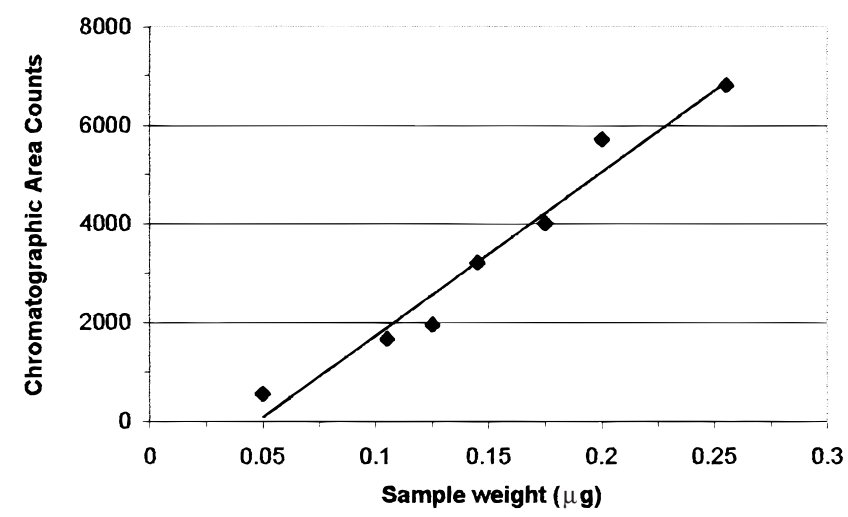

Figure 6. Chromatographic linearity $\left(R^{2}=0.963\right)$ of phenanthrene$d_{10}$ in DCM thermally desorbed after injection into a blank liner.

to that of the PAHs in the urban dust (0.05-0.25 $\mu \mathrm{g}$; Figure 6). Selection of a weight of phenanthrene- $d_{10}$ within this linearity could now be employed as an internal standard for the quantification of the PAHs.

Quantification of PAHs in the Urban Dust SRM. Five samples of $\sim 3 \mathrm{mg}$ of urban dust were prepared and spiked with $1 \mu \mathrm{L}$ of $150 \mathrm{ppm}(0.15 \mu \mathrm{g})$ samples of phenanthrene- $\mathrm{d}_{10}$ in DCM and then thermally desorbed in the usual way. The PAH peaks were then integrated and quantified relative to the phenanthrene$d_{10}$ peak. The quantified values are shown along with the certified values in Table 1. The quantified values are extremely good, and all of the calculated ranges (95\% confidence) overlap with the certified ranges except for chrysene. Calculated 95\%confidence limits are largest the greater the $\Delta R t\left(=R t_{(\text {target })}-R t_{\left.\text {(phenanthrene- } d_{10}\right)}\right)$ as system responses vary across the chromatograms. Applying a response factor adjusts for decrease in response between the standard and the target PAH, but these higher PAHs also suffered from variable molecular ion percentages over five quantification runs. This is due to low concentrations being measured, the reduction in response toward the high end of the chromatogram as well as increased background interference from the UCM of the chromatogram. Therefore, the PAHs of M W 276 have not been quantified.

\section{CONCLUSIONS}

We have shown thermal desorption GC/ M S to be a technique that can accurately quantify polycyclic aromatic hydrocarbons in an airborne particulate standard reference material using small amounts ( $1-5 \mathrm{mg})$ of material.

We have shown the following: (1) very good linearity for the total chromatographic response of the SRM $\left(R^{2}=0.948\right)$ over the range of sample weights (1-5 mg) as well as for a series of n-alkanes $\left(C_{20}-C_{33}, R^{2} \geq 0.931\right)$ in the microgram range and 10 PAHs ( $M$ W $=178-276, R^{2} \geq 0.971$ ) in the nanogram range. The linearity plots of the PAHs showed similar gradients illustrating comparability of all PAHs relative to a standard at all sample weights within the range. The higher PAHs could be quantified by applying response factors relative to the phenanthrene- $d_{10}$ standard; (2) a rough calculation of the total desorbable organic fraction ( $3.7 \%$ is comparable to the extractable (Soxhlet) fraction certified as $(4.6 \pm 0.4 \%$; (3) calculated concentrations of the eight PAHs with 95\%confidence limits coincide with the certified ranges apart from chrysene, which falls close to, but just outside of, the narrow certified range; (4) highly reproducible PAH concentrations ( $\mathrm{M} \mathrm{W}=178-228$, SD $\leq 0.228 \mathrm{mg} \mathrm{kg}^{-1}, \leq 7 \% \mathrm{M} \mathrm{W}=252 \mathrm{SD}$ $\leq 0.922 \mathrm{mg} \mathrm{kg}^{-1}, \leq 33 \%$ over five separate determinations using sample weights in the middle of the linearity range.

A simple calculation using the average deposit weights collected using low-volume sampling equipment in the London Air Quality N etwork (LAQN) and total organic carbon (TOC) calculations, carried out in conjunction with LECO Instruments (UK) Ltd., show that short sampling periods of 24-48 $\mathrm{h}$ provide sufficient material to fall within the linearity of the technique (range from 30 to $60 \%$ TOC-SRM calculated as $13-16 \%$ (certified as $16 \pm 5 \%$ ) .

The technique is at present being used for the routine determination of PAHs and other organic compounds in PM 10 at sites in London, providing much needed information on spatial and temporal trends in organic composition of airborne particulate matter, insight into potentially toxic compounds, and estimates of the major contributing factors.

\section{ACKNOWLEDGMENT}

The authors thank the NERC URGENT project for the funding to do this work and also South East Institute of Public Health (SEIPH), the City of Westminster Council, the London Borough of Greenwich Council, Pembrokeshire County Council, and Dianne Hall (BP) for their continued support of this work. We also thank LECO Instruments (UK) for their help in the TOC analysis work.

Received for review November 29, 1999. Accepted May 17, 2000.

\section{AC991372X}

